\title{
Modelo conceitual de mensuração do resultado econômico em entidades públicas
}

Carlos Alberto Grespan Bonacim

Doutorando em Controladoria e Contabilidade pela Faculdade de Economia, Administração e Contabilidade da Universidade de São Paulo - FEA/USP Professor da União de Cursos Superiores COC Ltda - UNICOC Avenida dos Bandeirantes, 3900 - Sala 41-bloco B. Monte Alegre. Ribeirão Preto/SP.

CEP: $14040-900$

E-mail: carlosbonacim@usp.br

Adriana Maria Procópio de Araujo Doutora em Controladoria e Contabilidade pela Faculdade de Economia, Administração e Contabilidade da Universidade de São Paulo - FEA/USP Professora da Faculdade de Economia, Administração e Contabilidade de Ribeirão Preto da Universidade de São Paulo - FEARP/USP Avenida dos Bandeirantes, 3900 - Sala 41-bloco B. Monte Alegre. Ribeirão Preto/SP. CEP: $14040-900$ E-mail: amprocop@usp.br

Claudio de Souza Miranda Doutorando em Controladoria e Contabilidade pela Faculdade de Economia, Administração e Contabilidade da Universidade de São Paulo - FEA/USP

Professor da Faculdade de Economia, Administração e Contabilidade de Ribeirão Preto da Universidade de São Paulo - FEARP/USP Avenida dos Bandeirantes, 3900 - Sala 41-bloco B. Monte Alegre. Ribeirão Preto/SP.

CEP: $14040-900$ E-mail: csmiranda@fearp.usp.br

\section{RESUMO}

A crescente atuação da sociedade nos processos de discussão e de tomada de decisões relacionados com as políticas públicas incentiva a gestão pública no Brasil a buscar mecanismos para demonstrar eficiência e transparência na aplicação de recursos (accountability). Este trabalho adotou o modelo conceitual de mensuração do resultado econômico em entidades públicas e teve como objetivo principal demonstrar que a teoria da Gestão Baseada em Valor pode ser adaptada como uma ferramenta para avaliação de desempenho de entidades públicas, adotando-se a perspectiva do cidadão como investidor. Os gestores de hospitais universitários públicos podem aprimorar o processo de tomada de decisões utilizando o cálculo do valor econômico agregado à sociedade, porque foi constatado que esta medida de valor tem sensibilidade para identificar os direcionadores de valor econômico a serem enfatizados na gestão de curto e longo prazos. Adicionalmente, o estudo revelou que a teoria da Gestão Baseada em Valor pode ser adaptada como uma ferramenta para avaliação de 
Modelo conceitual de mensuração do resultado econômico em entidades públicas Carlos Alberto Grespan Bonacim, Adriana Maria Procópio de Araujo, Claudio de Souza Miranda

desempenho de entidades públicas, adotando-se a perspectiva do cidadão como investidor.

Palavras-chave: Gestão Pública. Gestão Baseada em Valor. Resultado Econômico. Valor Econômico Agregado à Sociedade.

\section{Conceptual measurement model of economic result in public entities}

\section{ABSTRACT}

The increasing actuation of the society in the discussion processes and decision makings related to public politics stimulates public administration in Brazil to search for mechanisms to demonstrate efficiency and disclosure in resources applications (accountability). This work adopted the conceptual measurement model of economic result in public entities and it had as main objective to demonstrate that the theory of Value Based Management can be adapted as a tool for performance evaluation of public entities, adopting the perspective of the citizen as a shareholder. Public university hospitals managers can improve the decision makings process using the economic value added to the society calculation because it has been consisted that this measure of economic value has sensitivity in identifying which value drivers should be emphasized in short and long term management. Additionally, the study has demonstrated that the theory of Value Based Management can be adapted as a tool for performance evaluation of public entities, adopting the perspective of the citizen as a shareholder.

Key words: Public Administration. Value Based Management. Value Drivers. Economic Value Added To The Society.

\section{INTRODUÇÃO}

O presente artigo refere-se a um tema que vem merecendo crescente atenção na literatura econômica e empresarial (de gestão), seja do ponto de vista teórico ou empírico: a avaliação do desempenho econômico nas entidades públicas.

Desde a década de 90, a gestão pública no Brasil está passando por grandes mudanças incentivadas por reivindicações sociais que pedem maior eficiência, transparência e eficácia na aplicação dos recursos públicos.

A força da sociedade como agente de mudança emerge da superação de um regime militar, e foi construída ao redor da expansão da cidadania e do aprofundamento 
Modelo conceitual de mensuração do resultado econômico em entidades públicas Carlos Alberto Grespan Bonacim, Adriana Maria Procópio de Araujo, Claudio de Souza Miranda

da democracia, cujo marco formal é a Constituição Brasileira de 1988, conhecida como a "Constituição Cidadã", que incluiu mecanismos de democracia direta e participativa. Entre eles, o estabelecimento de Conselhos Gestores de Políticas Públicas, nos níveis municipal, estadual e federal, com representação paritária do Estado e da sociedade civil, destinados a formular políticas sobre questões relacionadas com a saúde, crianças e adolescentes, assistência social, mulheres, etc.

Essas transformações impulsionam o Estado brasileiro e as entidades públicas a se preocuparem com novos mecanismos de gestão voltados, principalmente, à implementação de processos de melhoria contínua, planejamento, avaliação e prestação de contas das atividades desenvolvidas.

A crença de que a melhoria das condições sociais do país passa pela participação ativa da sociedade civil, nos processos de discussão e de tomada de decisão relacionados com as questões e políticas públicas, determinou o desenvolvimento desta pesquisa que visa contribuir com uma visão mais integrativa da empresa pública e de seu relacionamento com o cidadão (contribuinte).

Todas as empresas necessitam de fundos para desenvolver suas atividades operacionais. Segundo a literatura, existem três formas legais básicas de organização de uma empresa: (i) firma individual - uma empresa de propriedade uma única pessoa que a opera visando a seu próprio lucro; (ii) sociedade - consiste de dois ou mais proprietários dirigindo conjuntamente um empreendimento, com fins lucrativos; e (iii) sociedade anônima - entidade empresarial.

\subsection{Questão da Pesquisa}

Considerando o interesse em contribuir para a melhoria do processo de gestão de avaliação de investimentos realizados pela sociedade (Estado) em entidades públicas, pretende-se, com esse estudo, responder à seguinte questão orientadora de pesquisa: como mensurar o valor econômico agregado à sociedade por uma entidade pública? 
Modelo conceitual de mensuração do resultado econômico em entidades públicas Carlos Alberto Grespan Bonacim, Adriana Maria Procópio de Araujo, Claudio de Souza Miranda

\subsection{Objetivo do trabalho}

Assim, em consonância com a questão estabelecida, o objetivo geral deste trabalho é: demonstrar como pode ser mensurado o valor econômico agregado à sociedade por uma entidade pública.

\section{METODOLOGIA}

A metodologia empregada neste trabalho é de pesquisa bibliográfica. Apesar de assumir a necessidade de uma pesquisa empírica, o assunto ainda é recente. Na visão de Santos e Parra Filho (1998), a pesquisa bibliográfica é necessária para se conhecer previamente 0 estágio em que se encontra 0 assunto a ser pesquisado, independentemente de a qual campo do conhecimento pertença.

De acordo com Fachin (2003, p. 102), a pesquisa bibliográfica se constitui num "conjunto de conhecimentos reunidos nas obras tendo como base fundamental conduzir o leitor a determinado assunto e à produção, [...] e utilização dos conceitos". Portanto, o apanhado da bibliografia em conjunto com comparações qualitativas, agrega valor à discussão existente.

Este estudo está organizado em cinco tópicos. Após a contextualização do problema na introdução, o segundo tópico apresenta uma compilação da literatura relevante existente sobre a Gestão Baseada em Valor, enquanto o terceiro tópico trata da avaliação de desempenho econômico em entidades públicas. O tópico quatro apresenta o desenvolvimento do indicador de valor econômico agregado por entidades públicas e o quinto tópico os comentários finais.

\section{A GEStÃo baseada EM VALOR E AVALIAÇÃo DE DESEMPENHO ECONÔMICO: O VALOR ECONÔMICO AGREGADO OU ADICIONADO (EVA®)}

O valor das empresas depende, em grande parte, das expectativas futuras de seu desempenho. Isso porque, segundo Hendriksen e Van Breda (1999, p. 281), "ativos são essencialmente reservas, benefícios futuros". Mencionam a definição do FASB, 
Modelo conceitual de mensuração do resultado econômico em entidades públicas Carlos Alberto Grespan Bonacim, Adriana Maria Procópio de Araujo, Claudio de Souza Miranda

encontrada em seu referencial conceitual, no SFAC 62: "benefícios econômicos futuros prováveis, obtidos ou controlados por uma entidade em consequência de transações ou eventos passados". Para o FASB, incorporar um benefício futuro provável é característica essencial dos ativos.

Copeland, Koller e Murrin (2000, p. 86) definem Gestão Baseada em Valor (GBV) como "[...] uma abordagem administrativa segundo a qual as aspirações da empresa, suas técnicas analíticas e seus processos gerenciais são alinhados para ajudá-la a maximizar seu valor". Trata-se de um processo integrador, não apenas de uma metodologia, estruturado a partir da identificação dos direcionadores de valor. Busca-se alterar comportamentos, a cultura da empresa. Para a GBV o maior objetivo de uma empresa é maximizar valor para o acionista.

Assim, o valor de uma empresa pode ser determinado por meio de modelos de avaliação. Entretanto, a aplicação de uma simples equação ou metodologia pode não ser considerada suficiente, porque existem fatores que não podem ser captados em modelos ou ferramentas que simplificam a realidade.

O EVA®, registrado como marca pela Stern \& Stewart, expressa o resultado apurado por uma empresa que excede o custo de capital dos credores e acionistas. É uma medida de criação de valor operacional após o desconto do retorno mínimo exigido pelos proprietários do capital investido no empreendimento. Os criadores do EVA® partem do pressuposto de que o lucro conforme apurado tradicionalmente pela contabilidade distorce seriamente os verdadeiros dados econômicos da empresa.

A principal crítica que fazem se refere à não consideração, pela contabilidade, do retorno exigido sobre o capital próprio, ou seja, a não consideração da remuneração que os provedores de capital devem exigir da empresa, conforme Ehrbar (1999); Rappaport (2001); Young e O'Byrne (2003) e Martin e Petty (2004).

EVA® representa uma medida de performance utilizada para monitorar a criação de valor de uma determinada entidade ou de unidades operacionais - departamentos (Shinder e Macdowell, 1999). Isso significa que sob a ótica do EVA®, a empresa estará agregando valor para os acionistas caso obtenha um retorno sobre o capital investido que exceda o custo do capital próprio e de terceiros combinados (Young e O'byrne, 
Modelo conceitual de mensuração do resultado econômico em entidades públicas Carlos Alberto Grespan Bonacim, Adriana Maria Procópio de Araujo, Claudio de Souza Miranda

2003).

O lucro residual abordado no modelo do EVA® quer dizer simplesmente que os lucros de uma companhia só começam a existir a partir do momento em que a empresa remunerou o capital nela investido. Assim, o lucro residual é zero se o retorno operacional for apenas igual ao exigido pelos proprietários de capital em troca do risco assumido (Bonizio et. al., 2006, p. 3).

Conforme Assaf Neto (2003, p.174), a mensuração do retorno econômico proposta pelo EVA® pode ser expressa da seguinte maneira:

$\mathrm{EVA} \circledast=\mathrm{LOP}-(\mathrm{CMPC} \times \mathrm{INV})$

Em que:

- LOP é o lucro operacional da entidade ajustado de modo que represente o resultado da organização por suas decisões de investimento, independente de suas decisões de financiamento;

- CMPC é o custo médio ponderado de capital, que como o nome expressa, é a média ponderada do custo de capital próprio e do capital de terceiros; e

- INV é o investimento de capital no empreendimento, dado pelo total do ativo reduzido do passivo de funcionamento (passivo não oneroso).

O resultado da formulação acima é o que os economistas denominam de lucro residual, que significa o resíduo depois que todos os custos tenham sido cobertos. Além dessa, existem outras formas de mensurar o resultado econômico pelo EVA® que chegam exatamente no mesmo resultado final.

Nessa pesquisa, porém, optou-se por adotar essa metodologia de cálculo por considerar que expressa mais claramente o conceito do resultado econômico, ou seja, mostra de maneira mais nítida que o resultado econômico de uma empresa só é obtido após as decisões de investimento (INV) e de financiamento (Custo Médio Ponderado do Capital, ou CMPC). 


\section{AVALIAÇÃO DE DESEMPENHO ECONÔMICO EM ENTIDADES PÚBLICAS: CONSIDERAÇÕES PRELIMINARES}

Para Olak (2000, p. 110), uma avaliação de desempenho deve ter indicadores que meçam, entre outras coisas: (i) eficácia: em que grau o produto (ou serviço, no caso dos hospitais) atende aos padrões estabelecidos consideradas as demandas de usuários e clientes; (ii) eficiência: em que grau o produto (ou serviço) está sendo produzido a um custo mínimo; e (iii) qualidade: em que grau o produto (ou serviço) é adequado ao uso pelo usuário (cidadão).

Corroborando com Pereira (1999, p. 189), entende-se que a avaliação de desempenho também faz parte de um processo em que se busca eficácia e eficiência. Desta forma, qualquer "avaliação de desempenho não tem outro propósito senão o de buscar a eficácia empresarial, nesse contexto entendido como a competência em obter continuidade em um ambiente dinâmico e de cumprir com sua missão" (Olak, 2000, p. 107).

Nesse sentido, o processo de avaliação de desempenho entre as empresas do setor privado e demais - organizações públicas sem fins lucrativos, possuem princípios semelhantes e que podem ser compatíveis. A Figura 1 evidencia os elementos básicos à prestação de contas das organizações públicas, como forma de assegurar a eficiência na aplicação dos recursos (investimentos feitos pela sociedade). 


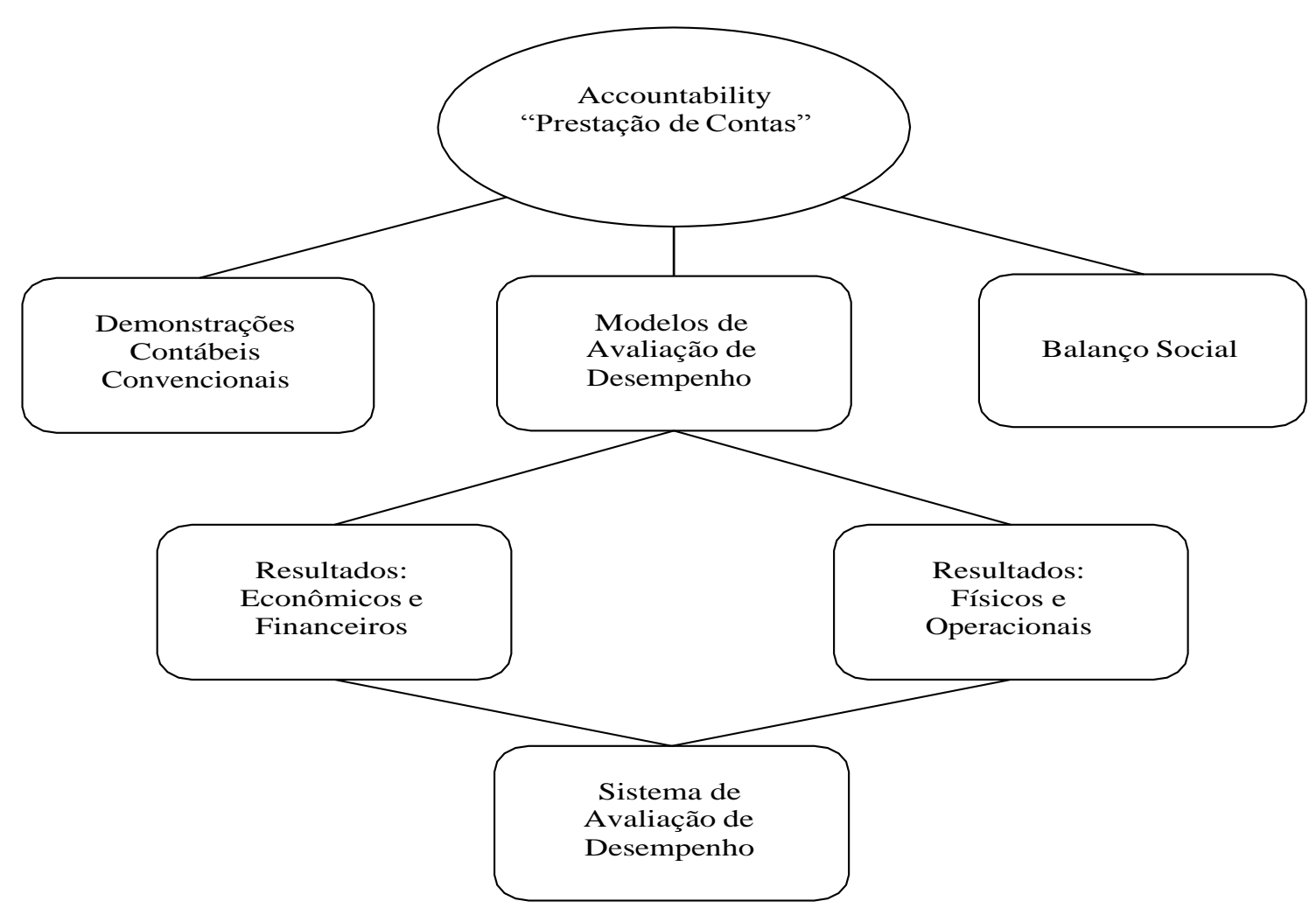

Figura 1 - Fluxo de Prestação de Contas e Avaliação de Desempenho no Setor Público Fonte: adaptado de OLAK (2000, p. 165).

$\mathrm{Na}$ leitura da Figura 1 verifica-se que o sistema de avaliação de desempenho deve "cruzar" resultados físicos e operacionais com os resultados econômicos e financeiros. Isso significa que o setor público deve prestar contas à sociedade tal qual empresas privadas devem prestar contas para os acionistas.

Normalmente as empresas privadas prestam contas, de forma espontânea, dos "resultados físico-operacionais" em um relatório complementar ao relatório da administração. Nesse relatório expõe-se aos acionistas dados agregados e indicadores como giro de estoques, prazo médio de pagamento, de recebimento, etc.

Ainda, segundo o autor, a prestação de contas no setor público é feita com base nas informações geradas pelos demonstrativos contábeis convencionais, pelo balanço social e por meio de um relatório de avaliação de resultados e desempenhos (relatório de atividades) e diretamente por meio dos sistemas orçamentários (empenho).

Entretanto, não se verifica a prestação de contas dos resultados econômicos, 
Modelo conceitual de mensuração do resultado econômico em entidades públicas Carlos Alberto Grespan Bonacim, Adriana Maria Procópio de Araujo, Claudio de Souza Miranda

considerando a eficiência no uso dos recursos investidos, por meio de relatórios gerenciais como é feito no setor privado. Existe a simples prestação de contas da aplicação do recurso.

Em uma analogia, uma entidade pública é obrigada a demonstrar para o Tribunal de Contas do Estado (por exemplo) que aplicou determinado recurso conforme previsto em orçamento: execução orçamentária via empenho. Por outro lado, essa entidade não informa o quão bem utilizou tal recurso, ou seja, se o recurso foi utilizado de forma eficiente.

Em uma outra analogia, no setor privado os acionistas usam os dados financeiros e econômicos (eficiência) publicados pela empresa para avaliar sua situação financeira e decidir se compram, vendem ou mantêm suas ações. No setor público, o cidadão era visto (até então) como apenas um contribuinte, o equivalente a um cliente no setor privado. Ele (cidadão), não necessitava de uma detalhada prestação de contas.

Para isso, Slomski (2005, p. 96) coloca o contribuinte como o acionista da "coisa pública". O autor traz a idéia de a administração pública ter de ser realizada como a administração de empresas que visam lucro. (Slomski 2005, p. 96).

[...] considera-se que ambos devem pautar-se eticamente e, se assim for, o Estado e suas entidades poderão ser governados como se administra uma empresa, haja vista que o objetivo da administração pública é o de maximizar o retorno do dinheiro arrecadado em favor de seus sócios (cidadãos).

Isso significa que a entidade pública deve prestar contas à sociedade tal qual empresas privadas devem prestar contas para o acionista. Assim, quando se pensa em calcular o valor econômico agregado por uma entidade pública, deve-se pensar no valor adicionado para a sociedade, ou seja, deve-se calcular a quantidade de valor econômico que a entidade agrega à sociedade.

Nas entidades públicas existe uma prestação de contas ao Tribunal de Contas do Estado no caso das subvenções (investimentos em custeio e para a aquisição de ativos fixos, equipamentos) realizadas pelo governo estadual. Tal prestação de contas se dá por meio dos relatórios de execução orçamentária (execução dos empenhos). 
Ou seja, existe, simultaneamente, a prestação de contas de resultados físicooperacionais e financeiros, conforme preconiza Olak (2000, p.164):

A avaliação de desempenho é, em última análise, uma questão de prestação de contas (accountability). Há, de um lado, o Poder Público financiando (fomentando) atividades e projetos sociais prioritários e de outro, as Organizações Sociais que têm sob sua responsabilidade um conjunto de recursos financeiros, tecnológicos, materiais, humanos etc., colocados à sua disposição. É evidente que nessa relação contratual há metas a serem alcançadas.

Carvalho, Souza e Slomski (2003, p. 3) destacam a necessidade de se criar relatórios gerenciais para evidenciar o resultado econômico produzido pela entidade pública.

Para que se possa ir além dos instrumentos da administração burocrática, para a prestação de contas, se faz necessário que administradores públicos criem dinâmicas que evidenciem seus resultados de maneira diferente daquelas que a regra, a norma e os padrões pressupõem. Para tanto, é imperativo que se produzam resultados que não sejam os financeiros, mas sejam resultados gerados pelo processo de mensuração de itens econômicos.

Assim, as entidades do Estado deveriam sempre mostrar para a sociedade o retorno proporcionado pela gestão pública. Esta não é uma tarefa simples, dada a dimensão da máquina estatal. Mas quando se divide a máquina em pequenas partes a tarefa torna-se possível.

Fica ainda mais simples quando a gestão da entidade pública é independente, ou seja, tem sua própria contabilidade e seus próprios controles de gestão. Assim, as adaptações propostas para cálculo do valor econômico agregado nesse estudo são para demonstrar a eficiência da entidade pública na gestão de recursos que the são concedidos pela sociedade.

Por outro lado, deve-se ter muito cuidado ao atrelar a existência de lucro a 
Modelo conceitual de mensuração do resultado econômico em entidades públicas Carlos Alberto Grespan Bonacim, Adriana Maria Procópio de Araujo, Claudio de Souza Miranda

ineficiência no alcance dos objetivos sociais. Realizando uma análise mais detalhada da Demonstração do Resultado do Exercício (DRE), pode-se encontrar uma abordagem diferente para a questão do lucro, tanto para empresas privadas, quanto para públicas e/ou sem fins lucrativos, conforme pode ser acompanhado na figura 2 a seguir:

\begin{tabular}{|c|c|}
\hline Estrutura básica de um a D R E & $\begin{array}{c}\text { E feitos na com } \\
\text { unidade }\end{array}$ \\
\hline Receita das Vendas & $\begin{array}{c}\text { Atendimento às } \\
\text { necessidades dos Clientes }\end{array}$ \\
\hline $\begin{array}{r}\text { ( - ) Custos da Mercadoria Vendida (C M V) } \\
\text { ou Custos dos Servicos Prestados (C) }\end{array}$ & $\begin{array}{c}\text { Remuneração de Fornecedores e } \\
\text { outros prestadores de serviços }\end{array}$ \\
\hline \multicolumn{2}{|l|}{$(=)$ Lucro Bruto ( - ) Despesas: } \\
\hline Administrativas (Salários) & Remuneração de Funcionários \\
\hline Vendas (Comissões) & Remuneração de Vendedores \\
\hline \multicolumn{2}{|c|}{$(=)$ Lucro Operacional $(-)$ Despesas Financeiras Remuneração de } \\
\hline \multicolumn{2}{|c|}{ Juros (B Bancos) ( =) Lucro A ntes do Impo\$to de Renda } \\
\hline ( - ) Imposto de Renda & Recolhimento de Impostos (Governo) \\
\hline ( = ) Lucro Líquido & Reinvestimento ou Sócios \\
\hline
\end{tabular}

Figura 2 - Estrutura básica de uma DRE e os efeitos da atuação de uma empresa privada na comunidade

Note-se que mesmo empresas privadas e, portanto, com fins lucrativos produzem benefícios sociais para a comunidade em que estão inseridas. Nesse caso tem-se o lucro como um resíduo da atuação de uma empresa, pois se deduziram da receita de vendas pelos serviços prestados ao mercado todos os insumos necessários: matéria-prima, mão-de-obra, juros, etc.

Desta forma, a existência de uma entidade, mesmo com finalidades lucrativas, produz benefícios à comunidade (externalidades positivas). Beneficiaram-se: os fornecedores de matéria-prima ou serviços, a população (emprego), os bancos e o governo, respectivamente.

Assim, a diferença fundamental entre as entidades privadas (com fins lucrativos) e demais entidades sem fins lucrativos (públicas, inclusive) reside no objetivo social, ou melhor, na missão. Isso porque, em ambos os casos, a continuidade do negócio depende do atendimento à missão (a que se propõe a instituição).

No caso das empresas privadas, a continuidade depende do cumprimento da 
Modelo conceitual de mensuração do resultado econômico em entidades públicas Carlos Alberto Grespan Bonacim, Adriana Maria Procópio de Araujo, Claudio de Souza Miranda

missão, sempre direcionada ao atendimento dos objetivos dos sócios. Nesse contexto, os sócios monitoram a todo instante o atendimento da missão por parte dos gestores.

Por sua vez, Drucker (2002, p. 79) trata da questão do desempenho e do resultado nas entidades sem fins lucrativos e afirma que, apesar de não ser prioridade neste tipo de instituição, os resultados "são muito importantes - e muito mais difíceis de se medir e controlar" do que na empresa privada.

O autor defende como a primeira pergunta a ser respondida na gestão da entidade: "como deve ser definido o desempenho desta instituição? ", isso é, deve-se definir o desempenho que, quando alcançado, operacionaliza a missão da instituição, pois este mostrará se os esforços estão realmente direcionados ao alcance da missão (normalmente uma causa social).

Em uma outra analogia, da mesma forma que os sócios monitoram e cobram o cumprimento da missão como pressuposto de continuidade nas entidades privadas, a sociedade deveria cobrar das organizações públicas o cumprimento da missão social cidadania.

Nesse contexto, o cálculo do valor econômico agregado à sociedade por entidades públicas proporciona parâmetros para uma avaliação econômica da eficiência na aplicação dos recursos da sociedade por parte destas instituições e, consequentemente, cria mecanismos para verificar o cumprimento da missão a que estas entidades se propuseram.

\section{DESENVOLVIMENTO DO INDICADOR DE VALOR ECONÔMICO AGREGADO POR ENTIDADES PÚBLICAS COM CÁLCULO FUNDAMENTADO NOS PRECEITOS DA GESTÃO BASEADA EM VALOR(GBV)}

As empresas privadas calculam o valor econômico agregado aos seus acionistas de diversas formas. Uma delas, bastante consolidada no meio empresarial, é por meio do indicador financeiro: Valor Econômico Agregado ou EVA®. Nesse contexto, faz-se a adaptação da metodologia de cálculo do EVA®, apresentado no tópico anterior.

É importante considerar que o lucro residual abordado no modelo do EVA® 
significa que a riqueza de uma companhia só começa a existir a partir do momento em que a empresa remunerou o capital nela investido. Assim, o lucro residual é zero se o retorno operacional for apenas igual ao exigido pelos proprietários de capital em troca do risco assumido.

Retomando, a mensuração do retorno econômico (EVA®) proposta no estudo, é expressa da seguinte maneira (melhor detalhado no tópico 1):

$$
. \mathrm{EVA}^{\circledR}=\mathrm{LOP}-(\mathrm{CMPC} \times \mathrm{INV}) .
$$

Com o intuito de adaptá-los às entidades públicas, cada um destes fatores (LOP, CMPC e INV) é analisado isoladamente, desenvolvendo os indicadores sintetizados nos Quadros 1 e 2: (i) valor econômico agregado de curto prazo (VECP); e (ii) valor econômico agregado para a sociedade (VEAS).

O lucro operacional (LOP) é o resultado das decisões de investimento da empresa, ou ainda, é o resultado produzido pela atividade fim da empresa. De forma simplificada, pode ser entendido também como a diferença entre as receitas e despesas operacionais.

No caso da entidade pública também é possível encontrar o 'lucro operacional'. Basicamente, seria a diferença entre a receita pública e os custos (e despesas) operacionais na prestação do serviço público. Especificamente, nas entidades públicas existem os termos superávits e déficits. Assim, os termos lucro e superávit ou prejuízo e déficits não são comparáveis, cada qual tem seu significado: "lucro representa eficácia na empresa privada, superávit é o indicador de economia de recursos" (Slomski, 2005, p. 99): 
Modelo conceitual de mensuração do resultado econômico em entidades públicas Carlos Alberto Grespan Bonacim, Adriana Maria Procópio de Araujo, Claudio de Souza Miranda

A Contabilidade Pública brasileira é uma contabilidade orçamentária e os resultados apresentados são déficits ou superávits, evidenciando dessa forma, como foram consumidos os recursos disponibilizados pelo Principal ao Estado durante o exercício financeiro. Se houver excesso de consumo, apresenta-se déficit; se houver consumo inferior à disponibilização de recursos, apresenta-se superávit. No entanto o cidadão (Principal) está familiarizado com os termos lucro ou prejuízo.

Contudo, o conceito de receita para as entidades privadas não é o mesmo daquele utilizado na contabilidade pública. A receita contábil na entidade privada normalmente é o valor oferecido em contrapartida do bem ou serviço. $\mathrm{Na}$ entidade pública o valor oferecido em contrapartida do bem oferecido não é contabilizado. Conforme Slomski (2001), a receita pública não reflete o valor que o consumidor estaria disposto a pagar pelo bem ou serviço oferecido. (Slomski, 2001, p. 52).

Entretanto, quando se trata de entidades públicas, [...] o termo "receita" referese ao recebimento de impostos e às transferências correntes e de capital, tomando desta forma outra roupagem; caracteriza-se, então, como todas as entradas de recursos na entidade, independentemente da contraprestação de serviços ou de entrega de produto.

O autor vai além e propõe o cálculo do resultado econômico da entidade pública utilizando o conceito de receita da entidade privada. Para ele, o resultado econômico da entidade pública é a diferença entre a receita econômica e a soma dos custos diretos e indiretos identificáveis à área de responsabilidade que produziu tal receita (Slomski, 2001).

A receita econômica, por sua vez, "é o produto da multiplicação do custo de oportunidade que o cidadão desprezou ao utilizar o serviço público, pelos serviços que ele efetivamente tenha executado". Como custo de oportunidade o autor entende "o menor preço de mercado à vista atribuído ao serviço prestado ao cidadão com similar qualidade, oportunidade e tempestividades daquele desprezado por ele ao utilizar o serviço público" (Slomski, 2001, p.53-54). 
Modelo conceitual de mensuração do resultado econômico em entidades públicas Carlos Alberto Grespan Bonacim, Adriana Maria Procópio de Araujo, Claudio de Souza Miranda

Considere, a título de ilustração, um hospital público. Nesse caso, a receita econômica de um período representa o menor preço de mercado que um paciente pagaria para obter os serviços de saúde oferecidos, no mesmo período. Observando a realidade do setor, o serviço de menor preço com qualidade similar seria o oferecido pelos planos de saúde (Fregonesi; Bonacim e Araujo, 2006).

Como os planos de saúde geralmente utilizam a tabela de preços-padrão para os diversos tipos de serviços elaborados pela Associação Médica Brasileira (AMB), ela representa a referência (neste trabalho) para o cálculo da receita econômica do referido hospital público.

O conceito do lucro operacional do hospital é, então, definido pela diferença entre a receita econômica (quantidade de serviços prestados multiplicado pelos respectivos valores da tabela $A M B$ ) e os custos (e despesas) incorridos para oferecer o serviço ao usuário. Define-se assim, o segundo componente para o cálculo do EVA® dos hospitais.

O próximo componente do EVA® a definir é o Custo Médio Ponderado do Capital (CMPC). Deve-se observar como o Estado investiria o recurso se não o destinasse aos hospitais. Baseado no conceito de custo de oportunidade, propõe-se o uso da taxa básica de juros da economia brasileira determinada pelo Sistema Especial de Liquidação e de Custodia (SELIC).

Obviamente, o ideal seria o desenvolvimento de estudo para buscar uma taxa que realmente reflita o custo de capital dos hospitais baseado no modelo de precificação de ativos (Capital Asset Pricing Model, - CAPM), inclusive com a tentativa de desenvolvimento do fator de risco, denominado beta ( $\beta$ ). Entretanto, esse estudo adota a premissa de que a taxa SELIC representa o custo de Capital para o Estado de forma pertinente.

O último componente do EVA® a ser definido é o valor do o investimento (INV). De acordo com a teoria da Gestão Baseada em Valor, o investimento é dado pela soma do patrimônio líquido com o passivo oneroso da instituição. Então, no caso dos hospitais públicos, o patrimônio social acumula o investimento do Estado realizado diretamente no ativo permanente da organização e o superávit/ déficit acumulado. 
Assim, há duas possibilidades: (i) utilizar o gasto do Estado no período, ou seja, todo o investimento feito pelo Estado no hospital em determinado ano, resultando no valor agregado pela entidade na prestação do serviço público por período; e (ii) utilizar o valor do passivo oneroso somado ao patrimônio social como é proposto no EVA® original.

Como as duas possibilidades geram valores diferentes e com significados diferentes, a proposta deste estudo é adotar os dois valores como indicadores de desempenho. Os quadros 1 e 2 demonstram um resumo das medidas propostas no estudo.

\begin{tabular}{|c|c|}
\hline $\begin{array}{l}\text { Medida de } \\
\text { Valor }\end{array}$ & Metodologia de cálculo \\
\hline $\begin{array}{l}\text { Valor Econômico } \\
\text { Agregado de } \\
\text { Curto Prazo } \\
\text { (VECP) }\end{array}$ & $\begin{array}{c}\text { Receita Econômica } \\
(-) \text { Custos Operacionais } \\
(-) \text { Despesas Operacionais } \\
\text { (=) Resultado Econômico Operacional } \\
\text { Taxa SELIC } \\
\text { (x) Investimento feito pelo governo na entidade no } \\
\text { período (=) Custo de oportunidade do capital } \\
\text { do Estado } \\
\text { Resultado Econômico Operacional } \\
\text { (-) Custo de oportunidade do capital do Estado } \\
\text { (=) Valor Econômico Agregado de Curto Prazo } \\
\text { (VECP) }\end{array}$ \\
\hline
\end{tabular}

Quadro 1 - Medidas de cálculo do valor agregado para a entidade pública

Desta forma, o resultado originado da primeira possibilidade (gasto do Estado no período) é o valor econômico agregado de curto prazo (VECP). Representa o quanto a sociedade ganharia (ou perderia) no período por "terceirizar" (delegar uma obrigação do Estado para terceiros) a prestação de um serviço para uma entidade isolada. 
Modelo conceitual de mensuração do resultado econômico em entidades públicas Carlos Alberto Grespan Bonacim, Adriana Maria Procópio de Araujo, Claudio de Souza Miranda

\begin{tabular}{|c|c|}
\hline $\begin{array}{c}\text { Medida de } \\
\text { Valor }\end{array}$ & Metodologia de cálculo \\
\hline & $\begin{array}{c}\text { Receita Econômica } \\
(-) \text { Custos Operacionais } \\
(-) \text { Despesas Operacionais }\end{array}$ \\
$\begin{array}{c}\text { Valor Econômico } \\
\text { Agregado para a } \\
\text { Sociedade } \\
\text { (VEAS) }\end{array}$ & $(=)$ Resultado Econômico Operacional \\
& Taxa SELIC \\
& (x) Investimento total feito na entidade (Passivo \\
oneroso +PS) (=) Custo de oportunidade para a & Sociedade \\
Resultado Econômico Operacional \\
(-) Custo de oportunidade para a Sociedade
\end{tabular}

Quadro 2 - Medidas de cálculo do valor agregado para a entidade pública

Já o segundo resultado é o valor econômico agregado para a sociedade (VEAS), isso é, representa o valor devolvido para a sociedade por ela "deixar" o capital investido na entidade. Os Quadros 1 e 2 apresentam um resumo das medidas propostas no estudo. Mostra-se, então, a possibilidade de adaptar o EVA® para as entidades públicas.

As medidas de valor desenvolvidas neste trabalho, e apresentadas nos Quadro 1 e 2, representam uma importante contribuição enquanto ferramentas de avaliação de desempenho pelo fato de incorporarem o conceito de custo de oportunidade. Elas permitem uma análise mais segura do "quanto" do investimento público é devolvido para a sociedade.

Tais medidas de valor econômico demonstram o potencial das entidades públicas na prestação de serviços que agreguem valor, tal qual serviço privado, pois as medidas de avaliação de desempenho convencionais (lucro e suas variações) não consideram o custo de oportunidade do capital investido, sendo para as entidades públicas a taxa SELIC.

Quando o governo altera o valor da taxa SELIC, automaticamente afeta o custo do capital a ele confiado pela sociedade. As medidas de valor VECP e VEAS têm a sensibilidade de demonstrar os impactos proporcionados pelas políticas econômicas no valor econômico agregado pelas entidades públicas. 
Modelo conceitual de mensuração do resultado econômico em entidades públicas Carlos Alberto Grespan Bonacim, Adriana Maria Procópio de Araujo, Claudio de Souza Miranda

Assim, um aumento na taxa básica de juros aumenta o custo de oportunidade do capital investido pela sociedade, exigindo maior eficiência operacional (medida pelo Resultado Econômico Operacional) das entidades públicas, como acontece no setor privado.

As medidas de valor VECP e VEAS podem ser aplicadas tanto para a entidade como um todo (avaliação global do desempenho), quanto para divisões da mesma entidade (avaliação segmentada do desempenho) e proporcionar, em ambos os casos, uma visão sobre o resultado econômico.

Cumpre observar que existem dificuldades associadas ao processo de avaliação segmentada do desempenho, pois nem sempre é possível medir as saídas (outputs) de segmentos (ou departamentos) em termos monetários. E quando possível, mesmo muitas vezes não existe necessariamente relação com as entradas (inputs), conforme (Anthony e Govindarajan, 1998).

Além de servirem como base para a tomada de decisões pelos gestores, essas medidas (VECP e VEAS), por outro lado, favorecem a transparência na prestação de contas da entidade para com a sociedade, que pode avaliar a eficiência de uma entidade com a leitura do cálculo.

Assim, o valor apurado pelas medidas VECP e VEAS "[...] significa que o agenciamento está sendo a um custo menor que o preço de mercado" (Slomski, 2005, p. 100), remunerando inclusive o custo de oportunidade do capital investido pela sociedade. Ou seja, a entidade é eficiente na prestação de serviços à comunidade, tendo como base preços de mercado (benchmarking).

Por outro lado, no caso de valores negativos para VECP e VEAS, trata-se de algo equivalente a um "[...] prejuízo econômico, a sociedade poderá rever toda estrutura de agenciamento" (Slomski, 2005, p. 100). Isso significa dizer que a sociedade não deve continuar "terceirizando" a prestação de serviço público.

Não resta dúvidas de que as medidas VECP e VEAS são úteis e válidas. No entanto, pode-se prever que haverá dificuldades semelhantes com as encontradas pelas empresas privadas quando da adoção do EVA®, por exemplo, a adequação do sistema contábil e de informações. 
Modelo conceitual de mensuração do resultado econômico em entidades públicas

Carlos Alberto Grespan Bonacim, Adriana Maria Procópio de Araujo, Claudio de Souza Miranda

\section{CONCLUSÃO}

O interesse em realizar este estudo surgiu da crença de que a melhoria das condições sociais no Brasil necessita de uma postura ativa da sociedade civil, em especial em relação às discussões sobre as políticas públicas.

Especificamente, o desenvolvimento desta pesquisa procura contribuir com a visão de que os cidadãos (contribuintes, que disponibilizam os recursos para o Estado) podem ser equiparados aos proprietários das empresas no setor privado.

Pôde-se verificar através do referencial bibliográfico, que o conceito de valor econômico agregado, inicialmente desenvolvido para atender a necessidade dos acionistas em acompanhar o resultado de seus investimentos, pode ser adaptado para enfocar a necessidade da sociedade em acompanhar o seu investimento.

Desta forma, verifica-se a possibilidade de aplicação desse modelo empresarial em organizações públicas sem fins lucrativos.

Adotou-se como referencial teórico de análise o modelo conceitual de mensuração do resultado econômico em entidades públicas de Slomski (1996), por acreditar que é relevante tratar o tema "valor econômico agregado à sociedade por entidades públicas", considerando os aspectos contemporâneos da gestão pública brasileira, visto que a agenda democrática nacional tem reivindicado novos direitos sociais e políticos, participação social, transparência, accountability e eficiência na gestão dos recursos públicos.

Um ponto a se destacar é a questão da aproximação da gestão pública e da gestão privada, pois, a entidade privada, por força da concorrência, evoluiu muito em relação às metodologias de avaliação do desempenho, enquanto a gestão pública em algumas áreas fez o caminho inverso; muitas vezes por questões políticas, não existe interesse em mostrar o desempenho.

Espera-se ter evidenciado que as medidas de valor desenvolvidas na pesquisa (VECP e VEAS) representam uma importante contribuição enquanto ferramentas de avaliação de desempenho econômico e, pelo fato de incorporarem o conceito de custo de oportunidade do capital investido, elas permitem uma análise mais adequada do 
Modelo conceitual de mensuração do resultado econômico em entidades públicas Carlos Alberto Grespan Bonacim, Adriana Maria Procópio de Araujo, Claudio de Souza Miranda

"quanto" do investimento público é devolvido para a sociedade.

As medidas de valor desenvolvidas podem demonstrar se as entidades públicas têm agregado valor econômico na prestação de serviço à sociedade, ou seja, se o resultado apurado for positivo, a entidade gerou valor à sociedade excedendo a remuneração mínima exigida (SELIC). Por outro lado, se o resultado apurado for negativo, significa que a sociedade perdeu ao "terceirizar" a prestação de um serviço para uma determinada entidade. Em geral, VECP e VEAS são medidas que podem mostrar se a atuação de uma entidade está gerando ou destruindo valor à sociedade.

O aprofundamento do estudo do tema e, principalmente, a aplicação das medidas em estudos empíricos são recomendáveis, com o intuito de compreender e descrever o atual estágio de evolução do processo de avaliação econômica dos investimentos públicos, e fundamentalmente validar estas medidas (VECP e VEAS).

Também, com o intuito de contribuir para o desenvolvimento do referencial conceitual sobre o cálculo do valor econômico agregado à sociedade por entidades públicas, são sugeridas pesquisas que adotem como referencial de avaliação os retornos sobre os investimentos da sociedade em entidades públicas de diferentes setores econômicos.

Compete a sociedade cobrar do governo transparência e accountability na gestão pública. Por outro lado, é de responsabilidade da academia contribuir desenvolvendo ferramentas de avaliação de desempenho econômico para auxiliar os gestores públicos na tomada de decisões. Outras discussões podem ser incluídas ainda nessa proposta de cálculo do valor agregado pela entidade pública à sociedade, porque é importante mudar a forma de apresentação dos resultados das entidades públicas para a sociedade e para o próprio governo.

\section{REFERÊNCIAS}

ANTHONY, R. e GOVINDARAJAN, V. (1998). Management Control Systems. (9 ed.). New York, McGraw- Hil, 800 p.

ASSAF NETO, A. (2003). Finanças corporativas e valor. São Paulo, Atlas, 722 p. 
Modelo conceitual de mensuração do resultado econômico em entidades públicas Carlos Alberto Grespan Bonacim, Adriana Maria Procópio de Araujo, Claudio de Souza Miranda

BONIZIO, R. C.; BONACIM, C. A. G.; VELLANI, C. e AMBROZINI, M. (2006). Mensuração do resultado econômico: um estudo comparativo entre as metodologias do GECON e do EVA. In: Congresso USP de Controladoria e Contabilidade, 6, São Paulo. Anais.... São Paulo, USP, 15 p.

CARVALHO, E.M.; SOUZA, G. e SLOMSKI, V. 2003. A demonstração do resultado econômico como instrumento de avaliação de desempenho em entidades públicas de administração direta. In: Congresso USP De Controladoria e Contabilidade, 3, 2003, São Paulo. Anais.... São Paulo, USP, 2003, 15 p.

COPELAND, T.; KOLLER, T. e MURRIN, J. (2000). Valuation: measuring and managing the value of companies. (3 ed.). New York, John Wiley, $512 \mathrm{p}$.

DRUCKER, P.F. (2002). Administração de organizações sem fins lucrativos: princípios e práticas. São Paulo, Pioneira Thomson Learning, 174 p.

EHRBAR, A. (1999). EVA: valor econômico agregado: a verdadeira chave para a criação de riqueza. Rio Janeiro, Qualitymark, $184 \mathrm{p}$.

FACHIN, O. (2003). Fundamentos de metodologia. (4 ed.). São Paulo, Saraiva, 200 p.

FREGONESI, M. S. F. A.; BONACIM, C. A. G. e RARAUJO, A. M. P. (2006) Cálculo do Valor Econômico Agregado à Sociedade em Hospitais Universitários: o caso do Hospital das Clínicas da FMRP- USP. In: III Congresso Nacional de Excelência em Gestão - CNEG. Niterói, RJ. Anais... Niterói, RJ, UFF. 20 p.

GITMAN, L.J. (1997). Princípios de administração financeira. (7 ed.). São Paulo, Harbra, 841 p. GOVERNO FEDERAL. 2004. Disponível em: http://www.planobrasil.gov.br. Acesso em: 02/nov/2005.

HENDRIKSEN, E. S. e VAN BREDA, M. F. (1999). Teoria da Contabilidade. (5 ed.). São Paulo, Atlas. Tradução por Antonio Z. Sanvicente, 554 p.

IUDÍCIBUS, S.; MARTINS, E. e GELBCKE, E. R. (2003). Manual de Contabilidade das Sociedades por Ações. (6 ed.). São Paulo, Atlas, 778 p.

MARTIN, J. D. e PETTY, J. W. (2004). Gestão baseada em valor: a resposta das empresas à revolução dos acionistas. Qualitymark, Rio de Janeiro, $272 \mathrm{p}$.

OLAK, P.A. (2000). Bases para a eficácia na aplicação do contrato de gestão nas organizações sociais brasileiras. São Paulo-SP. (Tese de Doutorado). Faculdade de Economia, Administração e Contabilidade, Universidade de São Paulo, São Paulo, 234 p. 
Modelo conceitual de mensuração do resultado econômico em entidades públicas Carlos Alberto Grespan Bonacim, Adriana Maria Procópio de Araujo, Claudio de Souza Miranda

OLIVEIRA, D. P. R. (1999). Planejamento estratégico: conceitos, metodologia e práticas. (13 ed.). São Paulo, Atlas, 338 p.

PEREIRA, C. A. (1999). Avaliação de resultados e desempenhos. In: Controladoria: uma abordagem da gestão econômica. São Paulo, Atlas, 576 p.

RAPPAPORT, A. (2001). Gerando valor para o acionista: um guia para administradores $e$ investidores. São Paulo, Atlas, 224 p.

SANTOS, J. A.; PARRA FILHO, D. (1998). Metodologia Científica. São Paulo, Futura, $277 \mathrm{p}$.

SHINDER, M.; McDOWELL, D. (1999). ABC, the Balance Scorecard and EVA®: distinguishing the means from the end. EVAluation. Stern Stewart Europe limited. 1(2):118.

SLOMSKI, V. (1996). Mensuração do resultado econômico em entidades públicas: uma proposta. São Paulo, SP. (Dissertação de Mestrado). Faculdade de Economia, Administração e Contabilidade, Universidade de São Paulo, SP, 82 p.

.(2001). Mensuração do resultado econômico nas entidades públicas: uma proposta. Chapecó: Argos, 88 p.

. (2005). Controladoria e governança na gestão pública. São Paulo, Atlas, 146 p.

STERN, J. M. e SHIELY, J. S. (2001). The EVA challenge: implementing value added change in an Organization. New York, John Wiley \& Sons, 260 p.

YOUNG, S. D. e O'BYRNE, S. F. (2003). EVA e gestão baseada em valor: Guia prático para implementação. Porto Alegre, Bookman, $422 \mathrm{p}$.

Data de Submissão: 26/05/2008

Data de Aceite: 05/08/2008 